\title{
FIVE REASONS TO PROMOTE OPEN ACCESS AND FIVE ROADS TO ACCOMPLISH IT IN SOCIAL AND CULTURAL SCIENCE
}

\author{
Chris Armbruster \\ http://homepage.mac.com/clcrossbow/ \\ http://ssrn.com/author $=434782$
}

\author{
Robert Schuman Centre for Advanced Studies \\ European University Institute \\ Via delle Fontanelle 20, I - 50016 San Domenico \\ chris.armbruster@iue.it
}

\begin{abstract}
Economists have done most to innovate scholarly publishing and communication by switching to Open Access. In cultural studies, history, law, political science and sociology, Open Access publishing is still an innovation at the margins. Yet Open Access is demonstrably the superior publishing model in the WWW Galaxy. Research networks, scholarly communities and academic tribes would do well to consider how to switch their communication and publishing to Open Access. The penalty for failing to do this will be decreased visibility and diminished impact, followed ultimately by a decline in public and philanthropic funding. For everyone, this article outlines the compelling reasons to switch to OA. Moreover, we have a common agenda when it comes to the means whereby Open Access is achieved. We will all suffer if a suboptimal lock-in occurs and innovation spaces are blocked. Therefore, full and partial OA solutions are evaluated. There is also a genuine need for collaboration when it comes to developing the next generation of overlay services such as literature awareness tools, information mining tools and search engines.
\end{abstract}

\section{Keywords}

Open Access, Social Science, Cultural Studies, Scholarly Publishing, Scholarly Communication, Peer Review, Open Science, Comparative Research, Globalization

Quotation permitted. Feedback, comments and criticism solicited.

Projected final revision of this working paper: 01 May 2006 


\section{Table of Contents}

\section{OPEN SCIENCE AND OPEN ACCESS}

The Budapest Open Access Initiative and The Berlin Declaration on Open Access to Knowledge in the Sciences and Humanities

Readers and Authors

\section{FIVE REASONS TO PROMOTE OPEN ACCESS}

Reason 1: Facilitating the advancement of knowledge claims

Reason 2: Enabling globally inclusive scholarly communication

Reason 3: Accounting for the rise of comparative and trans-national research

Reason 4: Increasing public visibility and enhancing impact for teaching and learning

Reason 5: Opening an innovative space for publishing, peer review and scholarly exchanges

\section{FIVE ROADS TOWARDS OPEN ACCESS}

1st road: Start an Open Access journal and give preference in submission to Open Access journals

$2^{\text {nd }}$ road: Deposit your papers in a disciplinary or institutional Open Access eprint repository

$3^{\text {rd }}$ road: Assert your authors' rights and retain the copyright when you publish

$4^{\text {th }}$ road: Work to ensure lifelong access for university alumni to electronic libraries

$5^{\text {th }}$ road: Help to spread discounted and free access in low-income countries

\section{OPEN ACCESS FOR OPEN SCIENCE}

Significant steps

Important URLS 


\section{OPEN SCIENCE AND OPEN ACCESS}

Scholars worldwide are concerned that the science commons are threatened as research data, results and publications are increasingly appropriated privately. Economists argue that scientific knowledge is a public good because of its indivisibility, limitless replicability and non-rivalness of use (David 2003, Nelson 2004). Legal scholars recognise the value of the creative commons as a resource for decentralised innovation (Lessig 2002, Wu 2006) in which patents and copyright exist as an incentive to guarantee supply, thereby stimulating creators, inventors and authors to contribute to the knowledge commons (Rose 1993). Sociologists argue that the ethos of science is to 'whittle down' patents and copyright and afford scholars a protection only as an incentive to disclose as early as possible their claims to knowledge (Sztompka 2005).

If scientific knowledge is a public good and scholars give away their publications for free ${ }^{1}$, then there is a strong case for Open Access as stated in the Budapest Open Access Initiative (2001):

An old tradition and a new technology have converged to make possible an unprecedented public good. The old tradition is the willingness of scientists and scholars to publish the fruits of their research in scholarly journals without payment, for the sake of inquiry and knowledge. The new technology is the internet. The public good they make possible is the world-wide electronic distribution of the peer-reviewed journal literature and completely free and unrestricted access to it by all scientists, scholars, teachers, students, and other curious minds. Removing access barriers to this literature will accelerate research, enrich education, share the learning of the rich with the poor and the poor with the rich, make this literature as useful as it can be, and lay the foundation for uniting humanity in a common intellectual conversation and quest for knowledge.

Open Access copyright and praxis was endorsed by the world's leading science organisations in the 'Berlin Declaration on Open Access to Knowledge in the Sciences and Humanities' (2003):

Open access contributions must satisfy two conditions:

1. The author(s) and right holder(s) of such contributions grant(s) to all users a free, irrevocable, worldwide, right of access to, and a license to copy, use, distribute, transmit and display the work publicly and to make and distribute derivative works, in any digital medium for any responsible purpose, subject to proper attribution of authorship (community standards will continue to provide the mechanism for enforcement of proper attribution and responsible use of the published work, as they do now), as well as the right to make small numbers of printed copies for their personal use.

2. A complete version of the work and all supplemental materials, including a copy of the permission as stated above, in an appropriate standard electronic format is deposited (and thus published) in at least one online repository using suitable technical standards

\footnotetext{
${ }^{1}$ Special thanks for helping with the project of bringing Open Access to social and cultural science are due to: Theresa Velden, Michael Nentwich, Katja Mruck, Stefan Gradmann, Jan Velterop, Melissa Hagemann, Robert Schlögel and Elmar Mittler. There is a companion paper 'Open Access in Social and Cultural Science: innovative moves to enhance access, inclusion and impact in scholarly communication'. It is available from SSRN http://ssrn.com/author $=434782$
} 
(such as the Open Archive definitions) that is supported and maintained by an academic institution, scholarly society, government agency, or other well-established organization that seeks to enable open access, unrestricted distribution, inter operability, and longterm archiving.

Scholars, libraries, universities, public research organisations, philanthropic foundations and research funding agencies around the world increasingly advocate Open Access e-publishing. When the comparatively well-funded US research libraries had to cancel journal subscriptions and reduce the purchasing of books, the libraries and their patrons began advocating Open Access. The Association of Research Libraries in the United States and the Ligue des Bibliotheques Europeennes de Recherche, have set up the Scholarly Publishing and Academic Resources Coalition (SPARC). SPARC and SPARC Europe are committed to enhancing broad and cost-effective access to scholarship. The International Federation of Library Associations says, that

- 'IFLA affirms that comprehensive open access to scholarly literature and research documentation is vital to the understanding of our world and to the identification of solutions to global challenges and particularly the reduction of information inequality;

- Open access guarantees the integrity of the system of scholarly communication by ensuring that all research and scholarship will be available in perpetuity for unrestricted examination and, where relevant, elaboration or refutation'.

\section{The Budapest Open Access Initiative and The Berlin Declaration on Open Access to Knowledge in the Sciences and Humanities}

The Budapest Open Access Initiative (BOAl), launched in 2001 with the aid of the Open Society Institute, has enabled the global coordination of the Open Access movement. Endorsed by diverse bodies such as the Australian Vice Chancellors Committee, Moscow State University, Kiel Institute for World Economics, Central European University and the MIT Libraries (along with 320 other institutions), BOAl has furthered the strategic objective of launching new journals and converting existing ones to Open Access. Another major milestone is the increasing Open Access archiving of so-called pre-prints and post-prints. While in the life sciences and medicine only post-prints are suitable for OA archiving (to minimise health risks), in social and cultural science there are good reasons to make working papers available as soon as possible. Globally, the Social Science Research Network (SSRN) and Research Papers in Economics (RePEc) make working papers available upon release as e-prints for downloading.

The move to Open Access was subsequently endorsed in the United States by research organisations, funding agencies and publishers in the Bethesda Statement (2002) and in Europe by the 'Berlin Declaration on Open Access to Knowledge in the Sciences and Humanities' (2003), which has also been adopted in China and India. 
The Berlin Declaration signifies the commitment of the world's leading science organisations and research funding agencies to Open Access. If they stick to their commitment, they alone can make Open Access the future standard of scholarly communication and publishing. Among the signatories are:

Max Planck Society, Fraunhofer Society, German Rectors' Conference, Leibniz Association, Helmholtz Association, Berlin-Brandenburg Academy of Sciences and Humanities, German Research Foundation, Volkswagenstiftung (all Germany); Centre National de la Recherche Scientifique (CNRS), Institut National del la Santé et de la Recherche Médicale (INSERM), Institut National de la Recherche Agronomique (INRA), Institut National de la Recherche en Informatique et Automatique (INRIA), Institut Pasteur (all France);

The Royal Netherlands Academy of Arts and Sciences (KNAW), Stichting SURF, Netherlands Organisation for Scientific Research (NWO); Austrian Science Fund (FWF), Austrian Rectors' Conference; Fonds National de la Recherche Scientifique (FNRS-Belgium), Fund for Scientific Research, Flanders; Association of Swedish Higher Education; Joint Information Systems Committee (JISC-UK); National Hellenic Research Foundation; Estonian Academy of Sciences; Chinese Academy of Sciences, National Science Foundation China (NSFC); Indian National Science Academy; Bibliotheca Alexandrina, Egypt (as well as 6 Dutch and 64 Italian universities)

European integration research has already taken to Open Access as the preferred mode of publishing, as is evident from projects such as European Integration online Papers (EioP), European Research Papers Archive (ERPA), Archive of European Integration (AEI), European Journal of Comparative Economics (EJCE) and Living Reviews in European Governance (LREG).

\section{Readers and Authors}

For readers Open Access means no subscription charges, no site licence fees and no pay-per-view charges. Articles and papers may be viewed, downloaded, printed, read and cited subject to proper attribution. The promise of Open Access is more than making pre-prints (like SSRN) and post-prints (like JSTOR) available. The aim is to create new overlay services that help to structure, organise and evaluate the literature in ways that make our searching and reading more effective and efficient. The Faculty of 1000 in the life sciences, with the support of over 1500 volunteers, all leading academics, provides an evaluation of and comment on the literature as it becomes available.

For authors Open Access enhances the potential impact, both academic and public: Over 3 million publications have been entered on getCITED by more than 350,000 authors. Moreover, the rise of comparative and trans-national research induces us to share ideas, data and results across borders. Globally inclusive scholarly communication has become desirable. In this context the promise of electronically based Open Access publishing is that it will reduce the delays and frustrations of the submission, peer review and publication process to the necessary minimum while enhancing the scope for exchanging for ideas across borders and disciplines. 


\section{FIVE REASONS TO PROMOTE OPEN ACCESS}

Open Access is desirable, feasible, affordable and achievable. The academic, ethical and strategic reasons for making Open Access the standard in scholarly publishing and communication are as follows:

\section{Reason 1: Facilitating the advancement of knowledge claims}

Science entails a commitment to the blind evaluation of knowledge claims, that is, independent of the status, location and origin of the claimant. Conversely this entails an obligation to facilitate the elaboration and refutation of knowledge claims across the globe. However, in the world of commercialized scholarly publishing, access to knowledge claims is increasingly closed off as reading becomes prohibitively expensive. As reading is curtailed, so is the capacity to meaningfully contribute to the elaboration or refutation of knowledge claims. Given the advances in technology and business, this curtailment is unnecessary.

"The substantive findings of science are a product of social collaboration and are assigned to the community. They constitute a common heritage in which the equity of the individual producer is severely limited. An eponymous law or theory does not enter into the exclusive possession of the discoverer and heirs, nor do the mores bestow upon them special rights of use and disposition. Property rights in science are whittled down to the bare minimum by the rationale of the scientific ethic. Scientists' claim to "their" intellectual "property" are limited to those of recognition and esteem which, if the institution functions with a modicum of efficiency, are roughly commensurate with the significance of the increments brought to the common fund of knowledge".

Robert K Merton "Ethos of Science" (1942)

Social and cultural knowledge emerges from comparisons, which presupposes open, international access. As knowledge is doubly hermeneutic - the metalanguage of social and cultural science intersects with meaning constituted by actors - it is crucial that worldwide actors in government, business and the third sector have access. European Integration online Papers (EloP), an interdisciplinary, peer-reviewed journal, is a fully linked OA e-journal that is accessible via all the important gateways such as the Social Science Information Gateway (SOSIG), the Directory of Open Access Journals (DOAJ), the European Commission Libraries Catalogue (ECLAS) as well as SSRN and RePEc. The efficiency of searching for and retrieving EloP articles is maximized. Visibility and impact of articles is enhanced. EloP features a comment function that allows for feedback to the author or, alternatively, a discussion with the wider scholarly community. EloP thus maximizes the connectivity, flexibility and interactivity that the WWW Galaxy offers.

The Social Science Research Network (SSRN) offers scholars the opportunity 
to host their working papers and their published papers, which are made available for readers to view and download free of charge. Viewing and downloading statistics, per author and paper, may serve to judge interest. Papers may be updated. SSRN requires scholars to register and ensures that submissions meet at least the quality standards of a working paper. Yet it is the author who must decide whether a particular paper is ready to be openly evaluated by peers. Beyond individual submissions, working paper series of university departments, public research organizations and international organizations are fed into SSRN. Research Papers in Economics (RePEc) is an open digital library to which a multitude of research institutions and publishers add their services while individual authors are able to submit their work. RePEc allows users to search for an OA version of any article. Whereas SSRN is an organized network based on a corporation, RePEc is an open network to which institutions may add their services and contents.

\section{Reason 2: Enabling globally inclusive scholarly communication}

Toll access to scholarly literature by subscription, site license and pay-per-view restricts the number of readers, thus impeding the dissemination of knowledge claims. This is not in the interest of authors as it reduces impact. Moreover, toll access is expensive as monopolists have little incentive to utilize electronic technologies to reduce costs but rather seek to augment revenue by charging separately for electronic copies. Price rises and the restricted flow of knowledge also impacts teaching arbitrarily as current literature is not available. Open Access is about equal access to knowledge. Equal and open access is the fundamental precondition to any higher education based on merit and achievement.

The UN World Summit on the Information Society has in its action plan, in the section on escience, the provisions to promote

A. Affordable and reliable high-speed Internet connection for all universities and research institutions to support their critical role in information and knowledge production, education and training, and to support the establishment of partnerships, cooperation and networking between these institutions.

B. Electronic publishing, differential pricing and open access initiatives to make scientific information affordable and accessible in all countries on an equitable basis.

C. The use of peer-to-peer technology to share scientific knowledge and pre-prints and reprints written by scientific authors who have waived their right to payment.

D. The long-term systematic and efficient collection, dissemination and preservation of essential scientific digital data, for example, population and meteorological data in all countries.

E. Principles and metadata standards to facilitate cooperation and effective use of collected scientific information and data as appropriate to conduct scientific research. 
Forum Qualitative Social Research (FQS) is a multilingual journal in German, English and Spanish. FQS publishes not only peer-reviewed articles on method and methodology, but also interviews, reviews, debates and conferences (more than 40000 downloads per month). Designed to exploit the speed, flexibility and interactivity of the WWW Galaxy, scholars collaborate trans-nationally and across disciplinary boundaries, also providing materials for teaching and learning.

The Scientific Electronic Library Online (SciELO) is a portal for OA e-journals that are assembled in national portals (e.g. Brazil, Chile and Spain). SciELO is available in Portugese, Spanish and English. SciELO is strong in the health and life sciences, but already features over 20 titles in the social sciences. SciELO helps scholars in transition and developing countries to increase visibility and impact, and is being adopted widely across Latin America (Venezuela, Peru, Mexico, Cuba, Costa Rica, Colombia and Argentina).

\section{Reason 3: Accounting for the rise of comparative and trans-national research}

With European integration, globalization and the fall of the Soviet empire we have seen an unprecedented rise of trans-national and comparative research. Yet research of this kind requires multiple participants and local knowledge, which is why the European Union has taken to sponsoring trans-national collaboration and international networks. It is imperative that research data and results are readily accessible.

At the OECD, a Meeting of the Committee for Scientific and Technological Policy at Ministerial Level stated with regard to access to research data that

'Ministers recognised that fostering broader, open access to and wide use of research data will enhance the quality and productivity of science systems worldwide.'

Communiqué on 'Science, Technology and Innovation for the 21st Century', 30 January 2004

Subsequently the Directorate for Science, Technology and Industry published a report on Digital Broadband Content: Scientific Publishing. It evaluates the 'Big Deal' that commercial publishers offer vis-à-vis Open Access publishing and archiving. The discussion of new and future value chains and business models implies that the OA model has the comparative advantage.

DSTI/ICCP/IE(2004)11/Final, 02 September 2005

The European Research Papers Archive (ERPA) was launched in 1998 by a group of institutions that are well known for their scholarly work on Europe and European integration. ERPA is an open access archive for working papers that have undergone peer review. ERPA may be joined by any university department, research institute or scholarly associations that can demonstrate its capacity to continuously supply working papers. The Archive of European 
Integration $(\mathrm{AEI})$ is an alternative to which registered users may upload their working papers if they meet scholarly standards. The AEI also features conference papers and paper series and archives EU documents. ERPA and $\mathrm{AEI}$ are linked as AEIplus, thus constituting a worldwide portal to research, documents and data.

The European Journal of Comparative Economics was launched by the European Association of Comparative Economic Studies (EACES), which has mobilized 85 referees to serve on an Open Access journal that publishes original articles twice a year. The EACES traces its origins to the rising scholarly interest in the political transition and economic transformation of central and eastern Europe after 1989. EJCE may be read across Europe and the world, independent of any institutional subscription.

\section{Reason 4: Increasing public visibility and enhancing impact for teaching and learning}

Research that is not being cited and used does not achieve a return for the sponsor. Hence public research funding agencies and philanthropic sponsors increasingly prefer Open Access as it maximizes citations and usage. The largest constituency to benefit from Open Access is students and their teachers. Only as the flow of knowledge becomes unrestricted around the world will

- All lecturers be able to base their teaching on the state of art in knowledge and methods;

- All universities offer their students equal access to knowledge;

- All Students for their self-study have access to current knowledge.

Wellcome Trust Open Access policy: Mandatory, not just requested

The Wellcome Trust, which funds Biomedicine, Technology Transfer and the Medical Humanities, spends over $£ 2 b n$ in a $5 y \mathrm{r}$ cycle. A participant in the Bethesda Statement on Open Access (2003), it has subsequently sought to develop a policy that would make results from the research it funds freely available. As of October 1, 2005, Open Access has become mandatory for all research funded by the Wellcome Trust. All grantees must comply and any resistance from publishers will not be accommodated. Within six months of publication the article must be deposited in PubMed Central (or PubMed Central UK, once it is operational).

Dspace@MIT of MIT Libraries hosts in Open Access faculty pre-and postprints, some dating to the first half of the $20^{\text {th }}$ century. OpenCourseWare (OCW) at MIT is a digital library of teaching materials. MIT faculty make available their syllabi, lectures and course materials. Some have been translated into Chinese, Spanish and Portugese. OCW was inspired by the Open Source software movement and operates on the basis of the Creative Commons Attribution Licence. MIT was an early sponsor of Creative Commons. MIT initially 
considered a commercial distance-learning venture, but found this was not a viable option given the commitment of the faculty to residential courses.

OCW has become a concept for the benefit of education. It makes the most advanced teaching and materials available for worldwide use, but it does so without seeking to substitute local educators and educational institutions elsewhere. OCW reinforces the public character of education, since the commercial use of its materials is prohibited.

\section{Reason 5: Opening an innovative space for publishing, peer review and scholarly exchanges}

Open Access facilitates the registration of knowledge claims and their distribution. It enhances academic impact and enables public visibility. It reduces overall cost and better protects authors' rights. Just as important is that scholars have begun taking control of and thinking about publishing and communication. Three major innovations, based on Open Acces, have occurred:

1. E-print repositories - to which pre-prints and post-prints are streamed or uploaded and which may be viewed and downloaded free of charge (like SSRN and RePEc);

2. Knowledge exchanges - which feature area reviews that delimit knowledge and method, contain extensive bibliographies and are suitable for teaching and learning (like OCW at MIT and Living Reviews);

3. E-journal platforms - for migrating and new journals with automated procedures for submission, review and publication (publishers like the Public Library of Science, Biomed Central and Berkeley Electronic Press).

As OA journals exist exclusively in the WWW Galaxy, they are able to considerably speed up the peer review process. Beyond that, some journals have also begun to experiment with open and/or signed peer review. This reflects not only an uneasiness with a lack of transparency in 'blind' peer review and possible bias, but also seeks to accommodate the move to more transnational and collaborative styles of research. 


\section{FIVE ROADS TOWARDS OPEN ACCESS}

Five roads may be distinguished that broaden access to scholarly knowledge. All of these un-restrict and thereby extend the flow of knowledge, yet only the first and second roads lead to genuine open access while the third and fifth are no more than temporary roads as the highways of $O A$ are under construction. Universal alumni access to publications and data would be compatible with a publishing model that seeks to recover cost only.

\section{$1^{\text {st }}$ road: Start an Open Access journal and give preference to submission to Open Access journals}

Starting an Open Access journal or converting an existing one has become straightforward. Whereas once cyber entrepreneurs had to worry about technology, software, standards and finance, today help and standardized solutions are there for everyone. Available from OSI, to get started, is a Guide to Open Access Publishing and Scholarly Societies and an Open Access Journal Business Guide. EloP, Living Reviews and FQS have developed software solutions that may be adopted. Financial support is available from OA signatory funding agencies and philanthropies. It is thus truly up to editors and their boards to convert existing journals or, alternatively, to set up a new journal in $O A$.

BioMed Central provides an OA platform with more than 120 journals, of which 65 are new launches. BioMed Central is based on Dspace, MITs OAI compliant off-the-shelf software. All journals on the platform must conform to the usual academic standards, though some have opted for open, signed and documented peer review. Peer review has been accelerated to 8 weeks. BioMed Central guarantees the permanency of published articles. BioMed Central levies a processing charge of $\$ 525-1500$ per published article. However, authors from the more than 500 institutional subscribers are not charged. Moreover, Norway and Denmark have national agreements with BioMed Central that exempt all authors from processing charges. Authors residing in a low-income country or suffering personal hardship have the processing fee waived.

When thinking of submitting an article it is possible to check with the Directory of Open Access Journals whether one of the over 500 listed journals in social and cultural science might be the best choice. Yet for some time to come OA coverage will be uneven. In that case one takes the $2^{\text {nd }}$ road. 


\section{$2^{\text {nd }}$ road: Deposit your papers in a disciplinary or institutional Open Access e-print repository}

In the first instance it is always possible to deposit the working paper with a disciplinary repository like SSRN or RePEc. The benefit is not only that results are made available immediately to the community, but also that the paper will have public exposure through alert services. When considering a journal for submission, it is possible to check on publisher copyright policy, especially with regard to self-archiving in an e-print repository. Preference may be given to publishers that have non-exclusive copyright agreements and permit pre-print and post-print archiving.

Dspace@MIT is built on open source software and may be federated by any academic institution wishing to host its own digital repository. Eprints, developed at Southampton University, is an established alternative system. The Max Planck Society also hosts an eDoc server and is actively developing the next generation of OA software. All of these organisations may be approached for consultation and licensing (free of charge).

Alternatively one's university or research organization may have an institutional repository. If so, the deposition of a pre-print or post-print will at least ensure that search engines will be able to locate the article. While it may be expected that a new generation of overlay services will soon appear in social and cultural science (of a quality like 'Faculty of 1000 '), currently the deposition with an institutional repository will not lead to the same kind of community exposure as with a disciplinary archive that has at least some simple literature awareness tools such as alert services and download counters.

In the worst case a publisher might send a copyright agreement that prohibits any other form of publishing. In that case, one takes the $3^{\text {rd }}$ road. 


\section{$3^{\text {rd }}$ road: Assert your moral rights as author and retain the copyright when you publish}

It is essential to assert the moral rights of the author, to retain the right to authorize others to make use of the work and to negotiate a time limit (of 6 or 12 months) after which the article may be posted to an OA archive. If an editor has accepted a paper for publication, then the publisher may be expected to respect the author's rights (who is, after all, giving away the work for free). If the publisher seeks to impose an exclusive and perpetual copyright, this should be made public to the journal editor and board as well as to an OA advocacy forum.

Creative Commons Attribution Licence

Creative Commons allows authors to legally license their work. Equivalent licenses are already available for 35 countries. All authors may utilize this license before they submit their work to any institutional repository, disciplinary archive or publisher. The Public Library of Science has adopted the Creative Commons Attribution License, which means in summary:

You are free to:

- copy, distribute, display, and perform the work

- make derivative works

- make commercial use of the work

Under the following conditions:

- Attribution. You must give the original author credit.

- For any reuse or distribution, you must make clear to others the license terms of this work.

*Any of these conditions can be waived if you get permission from the author.

Your fair use and other rights are in no way affected by the above. 


\section{$4^{\text {th }}$ road: Work to ensure lifelong access for university alumni to electronic libraries}

Universities increasingly seek to tie their alumni to the institution. Many offer continuing professional development, online continuing education and other knowledge and education services. Lifelong alumni access to electronic library resources, if costs are defrayed, could lead to economies of scale. Johns Hopkins University is already able to offer access to more than 8,000 full-text journals for $\$ 125$ per year. Indeed, given the ongoing worldwide expansion of higher education and the negligible cost of providing an additional electronic copy, lifelong alumni access should defray costs to a minimum.

Johns Hopkins University (Baltimore, Maryland) offers the following to its alumni:

- Primary Service - Free to all alumni, the Hopkins KnowledgeNET Primary Service offers users access to hundreds of academic journals, newspapers, e-books, and reference materials, as well as links to additional collections of online resources, digital libraries, and other Johns Hopkins publications. The Primary Service includes access to Project Muse and Annual Reviews (generally available by paid subscription only). Find an article from The New York Times or research a topic in the Columbia Encyclopedia or Merck Manual of Diagnosis and Therapy, all from the comfort of your home or office computer. Users can even e-mail a dedicated Hopkins KnowledgeNET librarian for assistance with online library services.

- Enhanced Service - The Hopkins KnowledgeNET Enhanced Service provides extensive resources central to a lifetime of learning. In addition to all of the resources available in the Primary Service, the Enhanced Service offers more than 8,000 full-text journals from licensed sources in business, education, engineering, humanities, international studies, medicine, nursing, public health, music, science and social studies. It also offers access to some 14,000 premium online books and other material, including e-books from leading publishers such as Harvard University Press, MIT Press, and The Johns Hopkins University Press. The Enhanced Service provides fax, toll-free telephone, and e-mail access to a dedicated Hopkins KnowledgeNET librarian. A one-year subscription to the Enhanced Service is only $\$ 125$ and used to defray the licensing fees for the resources.

However, in European countries national agencies and individual universities have signed agreements with publishers that prohibit granting alumni online eaccess. Yet Johns Hopkins shows that the Europeans simply signed on to a very bad deal. Universities around the world will need to renegotiate their contracts. In the age of alumni associations and continuing professional development it is essential for a university to enable off-site electronic access to its e-resources. 


\section{$5^{\text {th }}$ road: Help to spread discounted and free access in low-income countries}

UN initiatives have established discounted and free access in low-income countries. The Health InterNetwork Access to Research Initiative (HINARI) provides institutional access to over 2000 Biomed journals for local, non-profit institutions in developing countries: Access is free in countries with a GNP per capita less than $\$ 1000$; Access costs $\$ 1000$ p/a with a GNP per capita between $\$ 1000$ and $\$ 3000$. Conspicuous absences in the list of eligible countries are China, India and Brazil. HINARI relies on the goodwill of the commercial publishers and enjoys the support of the Gates Foundation, the Open Society Institute and The World Bank Group. Yet it has not been possible to develop a scientific, educational or practical mission. The website includes links to policy and practice, training and toolkits, but no actual information, offers or resources are available.

Access to Global Online Research in Agriculture (AGORA) operates in the Framework of the UN Food and Agriculture Organisation (FAO). AGORA provides free journal access to public institutions in 69 eligible countries with a GNI per capita per annum of US $\$ 1000$ or less at 31 December 2000. AGORA has been designed to increase the quality and effectiveness of agricultural research, education and training, and in turn, to improve food security.

On the other hand, the International Network for the Availability of Scientific Publications (INASP), a charity based in Oxford, specialises in the 'networking, accessing, sharing, and publishing of information' in developing and transition countries. The INASP vision is that 'all people are able to access and contribute information, ideas and knowledge necessary to drive sustainable and equitable development'. The Programme for the Enhancement of Research Information (PERI) is part of INASP. It has been launched to provide 'national access to international research findings'. Where research communities have ascertained to which journals and databases they require access, INASP negotiates access at preferential rates. At the same time INASP trains national and local facilitators so that the information resources and tools may be used effectively. 


\section{OPEN ACCESS FOR OPEN SCIENCE}

Open Access is technologically and economically feasible. The OA movement has been well organized. Unless strategic blunders are committed, the big commercial publishing houses are not in a position to stop OA, because numerous prestigious universities and research institutes have committed themselves to establishing institutional e-print repositories. With institutional repositories, the institution and its members, the authors, will obtain control over the copyright. If more philanthropic sponsors and public research funding agencies make OA mandatory, this will tip the balance in favour of OA.

'Increasing access charges and transaction costs arising from monopoly rights in data and information adversely affect the conduct of science, especially exploratory research programs. The latter are widely acknowledged to be critical for the sustained growth of knowledge-driven economies, but are most efficiently pursued in the "open science" mode'.

Paul A. David, 2003

\section{Significant steps}

In the meantime, there are a small number of very significant steps that each scholar may undertake. Please,

1. Make your work publicly available by depositing a copy in a disciplinary archive or institutional repository that guarantees Open Access and longterm archiving.

2. Sign the Budapest Open Access Initiative personally and enquire if your institution has plans for building an institutional repository - locally and nationally.

3. Ask if your scholarly association has considered switching its journal to Open Access.

4. Consider whether you are in a position to adopt the Creative Commons Attribution License (or an equivalent) for all your work.

Please consider the implication of the attribution license. If all scholars (or their institutions on behalf of them - on the precedent of non-exclusive patent licenses) were to adopt the attribution license, this would forever ensure that an Open Access archive could store a copy of your work. Commercial use by publishers would also be made possible, only not exclusively. More importantly, however, a whole new generation of competitive literature awareness tools and article databases could emerge as a level and global innovation space emerges. 


\section{Important URLs}

Access to Global Online Research in Agriculture (AGORA)

http://www.aginternetwork.org/en/

American Scientist Forum on Open Access

http://amsci-forum.amsci.org/archives/september98-forum.html

Archive of European Integration

http://aei.pitt.edu/

Berkeley Electronic Press

http://www.bepress.com/

Berlin Declaration on Open Access to Knowledge in the Sciences and Humanities

http://www.zim.mpg.de/openaccess-berlin/berlindeclaration.html

Biomed Central

http://www.biomedcentral.com/

Budapest Open Access Initiative

http://www.soros.org/openaccess/

Creative Commons

http://creativecommons.org/

Directory of Open Access Journals:

http://www.doaj.org

Dspace@MIT

https://dspace.mit.edu/index.jsp

Eprints

http://www.eprints.org/

European Commission Libraries Catalogue

http://europa.eu.int/eclas/

European Integration online Papers (EioP)

http://eiop.or.at/eiop/

European Research Papers Archive (ERPA)

http://eiop.or.at/erpa/ 
European Journal of Comparative Economics (EJCE)

http://eaces.liuc.it/default.asp

Forum Qualitative Social Research (FQS)

http://www.qualitative-research.net/fqs/fqs-eng.htm

getCITED

http://www.getcited.org/

Health InterNetwork Access to Research Initiative (HINARI)

http://www.who.int/hinari/en/

International Federation of Library Associations (IFLA)

http://www.ifla.org/V/cdoc/open-access04.html

International Network for the Availability of Scientific Publications (INASP)

http://www.inasp.info/

JSTOR

http://www.jstor.org/

Living Reviews of European Governance (LREG)

http://europeangovernance.livingreviews.org/

Max Planck Society eDoc

http://edoc.mpg.de/

OECD

http://www.oecd.org/document/0,2340,en_2649_34487_25998799_1_1_1_1,00.html

http://www.olis.oecd.org/olis/2004doc.nsf/0/cdcab59bc6365c1dc1257070005698e2?Op

enDocument

Open Access News

http://www.earlham.edu/ peters/fos/

Open Archives Initiative (OAI)

http://www.openarchives.org/

OpenCourseWare at MIT

http://web.mit.edu/ocw/

Public Library of Science (PLoS)

http://www.plos.org/

Research Papers in Economics (RePEc)

http://repec.org/ 
Romeo - Copyright and self-archiving policies

http://www.sherpa.ac.uk/romeo.php

Scientific Electronic Library Online (SciELO)

http://www.scielo.org/index.php?lang=en

Scholarly Publishing and Academic Resources Coalition (SPARC) http://www.arl.org/sparc/

Social Science Information Gateway (SOSIG)

http://www.sosig.ac.uk/

Social Science Research Network (SSRN)

http://www.ssrn.com/index sf.html

UN World Summit on the Information Society (WSIS)

http://www.wsis-si.org/

Wellcome Trust Open Access policy

http://www.wellcome.ac.uk/node3302.html 


\section{Bibliography}

Andermann, $\mathrm{H}$. and A. Degkwitz (2004) Neue Ansätze in der wissenschaftlichen Informationsversorgung. Ein Überblick über Initiativen und Unternehmungen auf dem Gebiet des elektronischen Publizierens. Historical Social Research 29:1:6-55

David, P. (2003) Can 'Open Science' be Protected from the Evolving Regime of IPR Protections? Working paper. http://www-econ.stanford.edu/faculty/workp/swp03011.pdf

European Science Foundation (2003) Open access: Restoring scientific communication to its rightful owners. ESF Policy Briefing 21 by A. Buckholtz et al. http://www.esf.org/publication/157/ESPB21.pdf

Gradmann, S. (2004) Vom Verfertigen der Gedanken im digitalen Diskurs: Versuch einer wechselseitigen Bestimmung hermeneutisch und empirizistischer Positionen. Historical Social Research 29:1:56-63

Harnard, S. (2003) For Whom the Gate Tolls? How and Why to Free the Refereed Research Literature Online Through Author/Institution Self-Archiving, Now.

http://www.ecs.soton.ac.uk/ harnad/Tp/resolution.htm

Harnard, S. et al. (2004) The Access/Impact Problem and the Green and Gold Roads to Open Access. Serials Review 30:4 http://eprints.ecs.soton.ac.uk/10209/

Krichel, T. and M.E.D. Koenig (2004) From open access to open libraries: claims and visions for Open Academic Libraries. In Proceedings International Conference of Digital Library: Advance the Efficiency of Knowledge Utilization, Beijing (China)

http://eprints.rclis.org/archive/00002202/

Lawrence, S. (2001b) "Free online availability substantially increases a paper's impact", Nature Web Debates

http://www.nature.com/nature/debates/e-access/Articles/lawrence.html

Lessig, L. (2002) The future of ideas: the fate of the commons in a connected world. New York: Vintage Books

Merton, R.K. (1942) The Ethos of Science. Republished in On Social Structure and Science.

Edited by P. Sztompka (1986) Chicago: University of Chicago Press

Nelson, R.R. (2004) The market economy, and the scientific commons. Research Policy 33:455471

http://ideas.repec.org/p/ssa/lemwps/2003-24.html

Odlyzko, A.M. (2002) The Rapid Evolution of Scholarly Communication. Learned Publishing 1:719

http://www.si.umich.edu/PEAK-2000/odlyzko.pdf 
OECD (2004) Digital Broadband Content: Scientific Publishing (by John Houghton and Graham Vickery) DSTI/ICCP/IE(2004)11/Final http://www.oecd.org/dataoecd/42/12/35393145.pdf

OECD (2005) Principles and Guidelines for Access to Digital Research Data from Public Funding: Promoting International Co-operation in the use of Scientific Data Resources http://www.oecd.org/document/0,2340,en_2649_34487_25998799_1_1_1_1,00.html

Open Society Institute (2003) Open Access Publishing and Scholarly Societies v 1.0 http://www.soros.org/openaccess/scholarly_guide.shtml

Open Society Institute (2004) Guide to Business Planning for Converting a Subscription-based Journal to Open Access v3 http://www.soros.org/openaccess/oajguides/index.shtml

Open Society Institute (2005) A Guide to Institutional Repository Software v3.0 http://www.soros.org/openaccess/software/

Rose, M. (1993) Authors and owners: the invention of copyright. Cambridge, MA: Harvard University Press

Schlögel, R. and T. Velden (2004) Berlin 2 Open Access: Roadmap Proposal http://www.zim.mpg.de/openaccess-cern/ presentation-oa2berlin-roadmap-proposal.pdf

Suber, Peter (2004) Promoting Open Access in the Humanities. Working paper http://www.earlham.edu/ peters/writing/apa.htm

Swan, A. and S. Brown (2004) JISC/OSI Journal Authors Survey Report. Truro: Key Perspectives Ltd.

http://www.jisc.ac.uk/uploaded documents/JISCOAreport1.pdf

Sztompka, P. 2005 Trust and Social Capital in Science: R. K. Merton's Inspirations. Working Paper

Wu, T. (2006) Intellectual Property, Innovation, and Decision Architectures Virginia Law Review 92:3

http://ssrn.com/abstract=726561 